\title{
Research on the Innovative Design of Bedroom Furniture for physically Handicapped Students
}

\author{
Huaqing Wang ${ }^{1, \text { a }}$ \\ ${ }^{1}$ Leshan Normal University, Sichuan, Leshan, 614000 \\ ${ }^{\mathrm{a} e m a i l,}$
}

Keywords: Physical Handicapped Students; Bedroom Furniture Design; Innovation Research

\begin{abstract}
Disability groups are a particularly difficult group that requires special care and attention. In this paper, the design of the bedroom furniture for the physically handicapped students is taken as the research core. From the behavior and psychological characteristics of the special group of the disabled, the paper focuses on the design pattern of the bedroom furniture suitable for the physically handicapped students, and puts forward the innovative design method according to the furniture design principle of the disabled group.
\end{abstract}

\section{Introduction}

According to the newly revised "People's Republic of China Persons with Disabilities Protection Law" on the definition of "disabled", the disabled refers to the psychological, physical, human structure, an organization, function loss or abnormal, all or part of the loss of normal those who are engaged in a certain type of activity generally include vision disability, hearing disability, language disability, physical disability, mental disability, mental disability, multiple disability and other disability.

Among the many groups of people with disabilities, physically handicapped groups, especially those with lower limb disability, usually need wheelchair activities, self-care ability is better than other disabled groups, can meet the special education school and normal school life, so for the physically handicapped students bedroom furniture innovation design research is more feasible and popular. As a vulnerable group, the research on the design of the furniture for the disabled students needs high attention and reflection. It embodies the concern of the people in the society. The designers use the humanized design to silently convey the care and love of the disabled group.

\section{The Behavior and Psychological Characteristics of Physical Disability Students}

The lack of physical function makes the disabled students more sensitive to the behavioral and psychological characteristics than ordinary students. To understand the physical difficulties of students in the use of bedroom furniture, we must profoundly understand their behavior and psychological characteristics, in this basis to make accurate judgments.

Due to physical defects, physically handicapped students in the study and life will encounter many ordinary people cannot imagine the difficulties, they will self-doubt, self-blame, that since the people; some moral qualities of the normal misunderstanding, discrimination will increase their inferiority complex, so that their inner fragile do not love with people, lonely introverted, rhetoric, lonely. These are not only the physical and psychological characteristics of physically handicapped students, but also common in the disabled group. Physical obvious defects, will make the physical disability students too concerned about the physical state of the body, very concerned about others on their own evaluation and ideas, often once the self-esteem is damaged, it will soon show dissatisfaction, resentment of excitement, and even take a counterattack means to vent revenge, their behavior is impulsive, emotional instability.

Of course, different types of disabled groups will also show different personality traits. Visually handicapped and language disability students are generally happy to communicate with people through the sign language and the character is more outgoing, warm and straightforward. The students who are visually handicapped and linguistic disability are generally willing to 
communicate with each other through sign language. The physically handicapped students tend to stubborn character, self-restraint ability, often encounter difficulties when they want to solve their own problems do not like to accept their help, to prove their ability is not worse than normal people.

Because of the restrictions on the exchange, the disabled group is always living in a small circle, which created them with ordinary people not the same character and behavior. In the study of furniture design, we should give full consideration to the behavior of physical disability students, psychological characteristics and the relationship between the environment, in the furniture design to be fully respected, care and help.

\section{Design Status and Design Principles of the Bedroom Furniture for Physical Disability}

Design Status. Market is by product, product development is by design. And the current market sales of hot indoor furniture design in stark contrast, the disabled group of furniture design market is almost blank, very few people interested. As of now, the domestic market supply of disabled goods and services for the disabled groups is also largely unable to meet the growing needs of disabled groups, disabled groups of furniture facilities and other goods development long-term attention, disability groups, industrial development and consumption of a huge gap between the supplies. The current situation of disabled groups in a single form of life, a single type, a single function, the lack of high-tech content, physically handicapped student groups and even disabled groups of furniture demand is small, and the demand is not clear, making the furniture design industry research in these areas is still relatively small, resulting in the design of the guide is not obvious, cannot meet the needs of users.

Therefore, whether it is from the humanistic care or business level, the innovative development of the disabled furniture industry is very worthy of research projects, both to help disabled students and even the elderly groups to improve their quality of life, but also by targeting Business opportunities, dig out a huge development potential of the sales market.

Design Principles. Furniture as a daily necessity, the design process should always adhere to the "people-centered" design concept. Based on the objective physical characteristics of physically handicapped students, the bedroom furniture design is designed to optimize the design of all objects for physically handicapped students. In summary, the following design principles are followed:

Accessibility is the primary principle that should be followed in designing disabled products. Disabled people due to physical and psychological changes in the activities of the existence of many difficulties, normal people can naturally use things, for them there will be a lot of inconvenience. Bedroom furniture design should be committed to the elimination of all obstacles, dangerous goods, and fully establish the "barrier-free" product design concept, to use wheelchairs, crutches and other physically handicapped students, always empathy for the sake of special people.

Physical handicapped students due to physical factors, in the open door, push and pull drawers and other aspects of the plight cannot be vigorously. Based on this, the bedroom furniture design as much as possible to allow physically handicapped persons always maintain a most effortless limb operation action, in line with the disabled body movement function based on the use of appropriate operating force, reduce the number of repeated actions to reduce the sustained physical strength load. In the furniture size, shape, etc., to meet the special physical size of physically handicapped students, so that it is enough, pull up, playing open, according to the move, the use of light, smooth and natural.

The care of students with physical disabilities is also concentrated in the comfort of furniture design, first, furniture design to follow the comfortable and beautiful, relaxed and natural style, color coordination, furniture, shape, material texture and furniture functions, harmony, so that users in the use of the process to feel comfortable, considerate and thoughtful; Second, beds, mattress design to be ergonomic, especially mattress design to meet the curve of the back of the body, with the most appropriate softness Support students from the body to help students with disabilities to achieve a comfortable lying position, while the high efficiency of sleep while promoting healthy development.

Protection of physical disabilities in the bedroom furniture design is extremely important, 
physically handicapped students spend more than a dozen hours a day in the dormitory life study, enhance the safe design of the dormitory is necessary. Designers should consciously create some protective facilities, such as furniture materials to avoid the choice of glass, metal materials, furniture, a number of fixed handrails, etc., thus adding to protect the user's function to prevent student operation mistakes, to avoid causing more damage.

Physical design of the physically handicapped group on the basis of the above principles, but also in accordance with the size of the disabled to functionally self-designed to improve their own self-care ability, to play self-initiative, do whatever things to establish the self-confidence and survival value of the disabled group, there will be no abandoned negative psychology, to a positive attitude to meet the future life.

\section{The Innovative Design Approach of Physical Difficulties Students in the Bedroom Furniture}

In view of the current market space for the design of indoor furniture, the furniture designers focus on the use of psychological and behavioral habits of the physically handicapped students, and make a series of innovative research on the bedroom furniture design of the physically handicapped students, pay attention to grasp the details, try to use human Initiatives to create a comfortable and convenient living environment.

Material. Modern furniture, a wide variety of materials, varied, mainly metal, sheet metal, plastic, solid wood, inflatable, and several. For the physically handicapped students, the most suitable is the wood, bamboo, rattan furniture, these are the traditional furniture materials, natural wood texture, warm texture, fresh and natural vision, it is easy to create a sense of home and people feel pleasure. At the same time these natural materials have not been deep processing, with environmental protection and natural, will not damage the physical health of disabled people, in addition to these materials, especially bamboo, rattan made of furniture is also light and very suitable for light limbs use of disabled students.

In the protection of the external design of the furniture, the choice of sponge, fabric and other flexible, cushioning good material, wrapped in the outside of the furniture, these soft touch, visual warm material to avoid physical disability caused by physical damage.

Size. Designed for barrier-free furniture, designers should take full account of the rationality of the size of the furniture, the location of the furniture to consider whether the wheelchair can be successfully passed, and increase the auxiliary protective facilities. Bedroom furniture involved in the size of the main bed, desk, wardrobe, bookshelf and other four categories:

The length of the bed is the same as the average person, in the height of the wheelchair with a wheelchair to the height of close, generally about $500 \mathrm{~mm}$, easy to physically disabled students from the wheelchair to the bed. In order to facilitate its own to get out of bed alone, you can install on both sides of the bed can be equipped with movable handrails to help reduce the use of hand and body support force, sleep can also be set up on both sides of the armrest, from the protective effect, to prevent students rolling at night bed, causing damage. General bedroom lights are on the entrance of the wall, in order to reduce the number of physically handicapped people up and down the bed, can be set in each bed lighting, and equipped with pull-type switch, easy to disabled students do not get out of bed can easily switch lights. Bedside can also design a reasonable size of the board, easy to pick and place items, increase storage space.

Wheelchair disabled use of the desk need to consider the body sitting, wheelchair, desk three relations. Wheelchair disabled do not need to use the seat, so the lower part of the desk to set aside enough legs and wheelchair width of the space, the national standard wheelchair width is $620 \mathrm{~mm}-650 \mathrm{~mm}$, so the desk width is greater than $770 \mathrm{~mm}$; national standard wheelchair height is about 500mm, taking into account the height of the handrail, the height of the desk to about $800 \mathrm{~mm}$ is appropriate. Some of the desk above will be equipped with bookcases, bookshelves and other storage space, where the bookshelf can be set to pull down, by reducing the height of the wheel to facilitate the wheelchair disabled self-pick and place items.

Wardrobe design takes full account of the physically handicapped students sitting in a wheelchair on the activities of many factors. Wheelchair disabled because they cannot stand, must sit and hold 
items, and because of the leg factors, the body cannot be close to the wardrobe, the upper arm was diagonal, so the wardrobe the top storage compartment cannot exceed the height of the disabled, after calculation, the maximum height of the partition is less than $1200 \mathrm{~mm}$, and the bottom of the lower partition height cannot be lower than the disabled to sit and reach the height of the handle, calculated by the height of $497 \mathrm{~mm}$ or so, as the depth cannot be greater than $500 \mathrm{~mm}$. The closet door is preferably made of a sliding door made of lightweight material for easy opening and closing. The drawer cabinet can be designed as a pull-down or drawer. The height of the closet can be designed as a hanging clothes rack. Students with physical disabilities can use tools such as hanger to sit clothes into the closet, increase storage space, convenient and effort. Part of the lockers and table cabinets can also be designed to be mobile, so wheelchair disabled people do not have to pick up things.

Shape. Furniture design in the shape, size, function of three closely linked, different functions and size of the furniture profound impact on the formation of shape. It takes into account the psychological and physiological characteristics of the disabled and the student groups, the design of the bedroom furniture of the physically handicapped students from the level of art and design, adhering to a simple and intuitive, simple and natural design attitude to make reasonable adjustments to the furniture shape, to avoid the exaggerated style of exaggeration. Furniture corner cannot be designed to sharp edges and corners, and to unanimously smooth round use, to protect the use of physical safety of physically handicapped students will not be sharp and other injuries, scratches. Furniture handle volume should not be too small, folding furniture should not be too much, smooth lines simple and natural, both can save manufacturing costs, but also make indoor transparent and bright, simple and leisure.

Color. Physical design of the bedroom furniture, as far as possible to choose the purity and brightness of the lower color, soft and bright, elegant and smooth such as light blue, light green, beige, etc., to avoid the hospital equipment like a cold feeling serious, to ease the students nervous , To eliminate stress. Different functional areas of the bedroom can form a prominent and not garbled color contrast, highlighting and not dazzling, not only reflects the age characteristics of the young students’ vitality, but also the disabled students to bring positive psychological hints.

\section{Conclusion}

For disabled groups, furniture products are important partners in their daily lives; for physically handicapped students, bedroom furniture in their campus life has a pivotal role. At present, many living areas of the university campus have strengthened the regional barrier-free construction and bedroom furniture is also user-friendly design, fine details of the treatment to meet the physical groups of physically handicapped people's daily life, both to facilitate their own body, but also conducive to the safety management of staff.

With the domestic and international community on the disabled groups continue to profound care and attention, furniture design industry has always adhere to the humanistic care design, disabled group of furniture design as an important component of the furniture industry will change the situation neglected in the past, change have gradually improved and comprehensive, with humane, innovative and comfortable design presents a new development.

\section{Acknowledgements}

Fund Project: Leshan Teachers College results cultivation project, Research on the Humanized Design of Dormitory Furniture in Colleges and Universities Based on Multi - functional Collection. Number: S16026

\section{References}

[1] Zhang Fei, Cheng Jun-fei. Application of barrier-free design principle in elderly furniture[J]. Packaging Engineering, 2007, 28 (3): 18 -21. 
[2] Liu Lianxin, Jiang Ningshan. Introduction to barrier-free design. Beijing: China Construction Industry Press, 2004.

[3] Song Duanshu. Handicapped people's needs and humanization analysis[J]. Packaging Engineering, 20078: 56-59.

[4] Wang Xiaoxuan. Special education school teaching life integration unit design research [D]. South China University of Technology, 2012

[5] Zhang Jianmin. Elderly accessible interior design research [D]. Chongqing University, 2008 